\title{
A Study of Influence of Different Translation Aids on Chinese EFL Majors' Construal of the Original in C-E Translation*
}

\author{
Xiaonong Wang \\ School of Foreign Languages, Ludong University, Yantai, China; College of Foreign Languages, Nankai University, \\ Tianjin, China \\ Email: xnwang1726@163.com \\ Bo Chang \\ Multimedia Teaching Management Department, Ludong University, Yantai, China \\ Email:wuwawo@tom.com
}

\begin{abstract}
The student-translator's construal of the original informs his expression in translation, and their construal construction depends partly on various translation aids. Applying the four-dimension construal analysis framework of Cognitive Linguistics to analyzing the relevant experiment results, the study finds that compared with paper dictionaries, internet resources are more helpful in some ways to undergraduate Chinese EFL majors as C-E student-translators in construal of the Chinese original, thus more significant to them. As far as these learner-translators are concerned, the former can be more instrumental for their construal of the original in scope and specificity, reflected particularly in that the former can help them obtain their needed encyclopedic and specialized information to a greater extent. The two different aids do not produce noticeable difference in their prominence choice and their translation of the original expressions which require much creativity. In perspective, though there exists remarkable difference between the two groups of translators, this difference seems to have little to do with the different translation aids. It is also suggested thereby that more pedagogic efforts should be made to develop the learner-translators' ability to apply translation technology in using internet resources as translation aids for better performance in C-E translation.
\end{abstract}

Index Terms - C-E translation, construal, internet resources, paper dictionary, undergraduate EFL majors

\section{INTRODUCTION}

The translator's construal of the original text is the major source of information for his expression in the target language. Such construal construction depends partly on various translation aids, and this is true of either studenttranslators or professional translators. Internet resources and paper dictionaries are both translation aids which are often used by translation learners, including the undergraduate EFL majors in learning and practicing translation. Considering the features of the two types of aids, we have good reason to suppose that Internet resources and paper dictionaries are both tools which can aid the translation learners in construal of the original text and the former is more helpful than the latter. Relevant literature search results show that there have been few attempts to research and find out to what extent and in what aspects they are different in helpfulness to the learners. The present study will attempt to answer such questions on the basis of an empirical research informed by the construal theory of Cognitive Linguistics.

\section{THEORETICAL BASIS}

In this study, the author adopts the definition by Langacker (1987) of the term "construal" in Cognitive Linguistics, which refers to different cognitive subjects' power to cognize the same thing or scene in different ways. More specifically, it is a human cognitive ability to observe and interpret scenes, and when observing and explaining the same thing or state, different people adopt different scope, perspective, prominence, background and specificity. The cognitive power of construal is the way by which humans develop their conceptual system, semantic structure, and language, and consequently their ability to express ideas linguistically (Wang Yin, 2008). The cognitive subject's construal of things (including linguistic signs) mainly involves four dimensions: scope, perspective, prominence, and specificity. ${ }^{1}$ The scope refers to the speaker (cognitive subject)'s conceptual range configuration he decides on when he wants to express something or that activated by a linguistic expression when a reader reads it. When the cognitive subject tries to understand a linguistic expression, the scope is closely related with his past experiences and encyclopedic knowledge as well as the semantic background provided by the situational context where the expression is.

${ }^{*}$ The authors adopt the four construal dimensions framework put forward by Wang Yin (2008). 
After the speaker has decided on the scope, then he will proceed to decide on the perspective by which he expresses it. For a reader, the linguistic expression will activate his cognition of the perspective of the expression. The perspective of a text mainly concerns person and the grammatical subject of the sentences of it. As far as prominence and specificity are concerned, they are closely related. The speaker is impossible to express everything in the scope of a scene or thing. Instead, he can only select part of the information as the object of his attention and express that part according to specific purposes and that part of information will be the prominent. As far as a reader is concerned, the linguistic expression in a text is to the information it is able to activate in the mind of the reader what the tip of an iceberg to the whole iceberg. Prominence concerns mainly two aspects: explicit as prominent/implicit as non-prominent, and prominent to different stages of the process of a movement (Wang Yin, 2009). In specificity, what gets prominent is usually what needs to be observed in a scope more closely and described at greater length.

It can be reasonably assumed that in the process of translation as one of dynamic cognitive operation, the translator re-conceptualizes the linguistic signs of the original text in his mind and then re-verbalizes that result of reconceptualization incorporating those non-linguistic factors relevant with his translation task on the basis of the same cognitive mechanism, which will be embodied ultimately as a text in the target language (Wang \& Zhang, 2009). The process of re-conceptualization and re-verbalization in translation by the translator occurs in the translator's mental world (cognitive world) through a cognitive operation mechanism which can be explained by the conceptual integration theory (see Fauconnier, 1994). In terms of the construal theory, it involves a multiple process of construal of not only the linguistic signs in the original text but also many other relevant factors such as the target readership, the translation purpose, the use of the translated text, etc. The translated text is constructed by the translator mainly on the basis of his construal of the original text and his cognitive analysis (also construal) of the probable construal of his translation on the part of the target reader. Therefore, by analyzing the translated text, which is the realized visible result of invisible construal, we can know partly (actually we can only know partly) the translator's construal of the original text.

In construing a linguistic sign, the four dimensions will be involved almost simultaneously. However, for the convenience of analysis in our case, we treat them as separate aspects and regard them as analyzable elements respectively. In translation from Chinese into English, the relationship in scope between the Chinese original and the English translation is mainly represented by the degree in conceptual similarity between the Chinese expressions and their corresponding English versions. In perspective, we may pay attention to whether the original perspective is retained or changed. Prominence involves mainly different salience given to different stages of the movement or selection of different aspects in the scope activated by the Chinese original expression, and specificity concerns amplification or reduction in information (i.e. in words expressing notional concepts), which is not measured by the number of words actually used, for the Chinese language is a paratactic one, while the English language, a hypotactic one. The construal of the translator, as the cognitive subject in translating, occurs and is completed in his cognitive world and such process will keep renewing his cognitive world through assimilation and adaptation mechanisms.

\section{RESEARCH METHODS}

\section{A. Description of the Subjects in the Experiments}

The authors selected some Chinese EFL majors from the four classes (135 junior students of the year 2006 grade in total, who entered the first term of their third year) under their instruction in School of Foreign Languages, Ludong University, as the subjects in the experiments of the study. The basic standard of selection is their points they achieved in the TEM4 (a state English test for the second year EFL majors in a four year course of undergraduate study program), and the threshold is 70 points (the full mark is 100 points). There are totally 62 students who meet the standard. And from them, the authors selected further 20 students according to their student numbers at random, who were divided into two groups, i.e. Group One and Group Two, each with 10 students. The average achievements in TEM4 of the two groups are 73.3 and 73.9 respectively, and therefore we can accept that as two groups, they are equivalent in English proficiency. Before the series of experiments began, the subjects had learned four weeks of translation (two teaching hours per week) in a course of translation from English into Chinese, and thus they had acquired some basic knowledge of translation. All the subjects completed their introductory courses in computer technology and application, and they were familiar with the skills required in surveying useful information in internet. The two groups were asked to conduct the experiments in rotation: for example, in the first experiment, if Group One used internet resources, Group Two would use paper dictionaries, and in the second experiment, Group One would use paper dictionaries, and Group Two, internet resources. By such rotation, the possible influence of individual difference between the two sides in translation competence and computer application skills on the experiment results can be diminished to a minimum. In the period of experiments, the subjects were learning their various courses according to their regular teaching program.

Translation in essence is a process of conceptual integration, and there are many factors (sources of information) participating in the conceptual integration, which results in the translated version. Under the conditions of the experiments in the present study, we can regard the translated version as the result of integration of such main sources of information as the Chinese text, the relevant background knowledge accessible to the translator with regard to the translation task, which bears on the original author, the target reader, the use of the translated version, the medium, etc., and the relevant encyclopedic knowledge, both declarative knowledge of bi-lingual language, culture, and translation, 
and procedural knowledge concerning application of dictionaries and internet resources in translating practices. The two groups of subjects are quite similar in all the above aspects except the difference in using translation tools (paper dictionaries or internet resources in our case).

The information offered to the translators in the experiments include: the initiator of translation is the teacher; the English readership is supposed as the average native readers from the English culture who do not know or know little Chinese language; the translation form is full translation. The subjects' cognition of the supposed readership of their translations is based on their own experiences and structure of knowledge, and therefore, they have more or less difference in their analysis of their target reader. The authors, by pre-surveying in the internet, made sure that there were not English translations available correspondent to all the textual materials in Chinese for the experiments, which means that the subjects would have to translate completely by themselves and produce their own translations.

\section{B. Experiments}

In the study, the authors organized ten experiments conducted by the two groups of subjects respectively. The experiments were performed in the language lab with internet facilities in School of Foreign Languages, Ludong University. The period was ten weeks in the first term of the school year 2008-2009 of the university, and in every Tuesday afternoon of those weeks, the subjects met in the lab and conducted the experiments from 2:30 PM to 4:10 PM, each experiment lasting for 100 minutes of which 85 minutes were allotted for translating and the remaining 15 minutes for filling out their experiment reports. In every experiment, the subjects of the two groups translated the same Chinese original text (The Chinese originals were offered in complete texts, and the subjects were required to translate only the underlined sentences). According to the authors' understanding, by their experiences in teaching, of the subjects' translation competence, of the difficulty of the originals, and considering the time limit of the experiment, they chose relatively appropriate original texts for them to translate, the Chinese characters ranging from 230 to 325 .

On the basis of the typology of texts by Snell-Hornby (1995) in the light of the prototype category theory, and of the authors' analysis of the background knowledge and translation competence of the subjects, the selected Chinese texts, as the original, came from the three major text categories, i.e. special, general, and literary texts, which included one text in science and technology (A), one text in regulation (B), one text in (translation) theory (C), one text in commerce (D), one text in tourism (E), one text in journalism (F), two texts concerning current affairs (G; H), and two texts of literary prose $(\mathrm{I} ; \mathrm{J})$. Before every experiment, the Chinese text would be loaded into the E-mail shared by the authors and the subjects, and the subjects downloaded it from the E-mail box for the experiment. In experiment, the difference between Group One and Group Two is that when one group used paper dictionaries for reference (PD), the other consulted internet resources in translating (IR), and they would rotate with regard to their reference. The subjects translated independently, who were not allowed to exchange ideas in the experiment. Both groups used MS Word in word operation. After an experiment, subjects of both groups wrote their experiment report, which included their translated texts in English, their personal information (who translated?), text type (what type of text?), translation tools (which tool?), translation process (how was it translated?), and their reflections on the words and sentences they thought difficult to translate and their solutions. After each experiment, subjects in both groups emailed their reports to the designated mailing address. The authors collected the translated texts and after all those experiments, constructed a small corpus of 200 translated texts with 42,786 English words (For the codes of texts and subjects, see Table I).

TABLE I.

CODES OF TEXTS AND SUBJECTS

\begin{tabular}{|l|l|l|l|l|l|l|l|l|}
\hline & $\mathbf{1}$ & $\mathbf{2}$ & $\ldots$ & $\mathbf{1 0}$ & $\mathbf{1}^{\prime}$ & $\mathbf{2}{ }^{\prime}$ & $\ldots$ & $\mathbf{1 0}$ \\
\hline $\mathbf{A}$ & $1 a$ & $2 a$ & $\ldots$ & $10 a$ & $1^{\prime} \mathrm{a}$ & $2^{\prime} \mathrm{a}$ & $\ldots$ & $10^{\prime} \mathrm{a}$ \\
\hline $\mathbf{B}$ & $1 \mathrm{~b}$ & $2 \mathrm{~b}$ & $\ldots$ & $10 \mathrm{~b}$ & $l^{\prime} b$ & $2^{\prime} b$ & $\ldots$ & $10^{\prime} b$ \\
\hline $\mathbf{C}$ & $1 c$ & $2 c$ & $\ldots$ & $10 c$ & $1^{\prime} \mathrm{c}$ & $2^{\prime} \mathrm{c}$ & $\ldots$ & $10^{\prime} \mathrm{c}$ \\
\hline $\mathbf{D}$ & $1 \mathrm{~d}$ & $2 \mathrm{~d}$ & $\ldots$ & $10 \mathrm{~d}$ & $l^{\prime} d$ & $2^{\prime} d$ & $\ldots$ & $10^{\prime} d$ \\
\hline $\mathbf{E}$ & $1 e$ & $2 e$ & $\ldots$ & $10 e$ & $1^{\prime} \mathrm{e}$ & $2^{\prime} \mathrm{e}$ & $\ldots$ & $10^{\prime} \mathrm{e}$ \\
\hline $\mathbf{F}$ & $1 \mathrm{f}$ & $2 \mathrm{f}$ & $\ldots$ & $10 \mathrm{f}$ & $l^{\prime} f$ & $2{ }^{\prime} f$ & $\ldots$ & $10^{\prime} f$ \\
\hline $\mathbf{G}$ & $1 g$ & $2 g$ & $\ldots$ & $10 g$ & $1^{\prime} \mathrm{g}$ & $2^{\prime} \mathrm{g}$ & $\ldots$ & $10^{\prime} \mathrm{g}$ \\
\hline $\mathbf{H}$ & $1 \mathrm{~h}$ & $2 \mathrm{~h}$ & $\ldots$ & $10 \mathrm{~h}$ & $l^{\prime} h$ & $2^{\prime} h$ & $\ldots$ & $10^{\prime} h$ \\
\hline $\mathbf{I}$ & $1 i$ & $2 i$ & $\ldots$ & $10 i$ & $1^{\prime} \mathrm{i}$ & $2^{\prime} \mathrm{i}$ & $\ldots$ & $10^{\prime} \mathrm{i}$ \\
\hline $\mathbf{J}$ & $1 \mathrm{j}$ & $2 \mathrm{j}$ & $\ldots$ & $10 \mathrm{j}$ & $l^{\prime} \mathrm{j}$ & $2^{\prime} \mathrm{j}$ & $\ldots$ & $10^{\prime} \mathrm{j}$ \\
\hline
\end{tabular}

Note: A, B...: Codes of the Chinese texts; a, b...: Codes of English texts; 1, 2...: Codes of subjects in Group One: 1', 2'...: Codes of subjects in Group Two; 1a, 2a...: IR aided translations; 1'a, 2'a...: PD aided translations.

\section{DATa ANALYSIS}

\section{A. Analysis of the Four Dimensions of Construal and Findings}

The authors analyzed all the translated texts by sampling on the level of words and sentences. The way of sampling is: five words or phrases are selected from every Chinese original text mainly on the basis of the subjects' reports on difficult words or phrases (For example, 8 of PD subjects marked “雨帘” as “most difficult expression” and 6 of this 
group marked “你属龙, 我也属龙, 两条龙一起出动奔考场, 就该有大雨相随。” as “most difficult sentence”. In the IR group, there were 4 and 3 subjects respectively.) and the authors' analysis of the difficulty degree of the words and phrases for analysis in scope, prominence, and specificity, and one sentence in every Chinese original text (mainly Chinese sentences which are those with no explicit subject, with more than one subject, and with a topic-comment structure) for analysis of perspective. Here the author will take the tenth experiment for example and present the result of analysis in Table II, where the data order is the same as that of the subjects in the experiments.

TABLE II.

ANALYSIS OF THE TRANSLATIONS IN THE TENTH EXPERIMENT

\begin{tabular}{|c|c|c|c|}
\hline Dimensions & Examples & PD aided translation & IR aided translation \\
\hline \multirow{3}{*}{$\begin{array}{l}\text { Scope } \\
\text { [The } \\
\text { translations } \\
\text { with } \\
\text { equivalent } \\
\text { scope to the } \\
\text { original are } \\
\text { boldfaced } \\
\text { and the } \\
\text { figure in } \\
\text { the } \\
\text { brackets is } \\
\text { their } \\
\text { number] }\end{array}$} & $\begin{array}{l}\text { (路面) 积水 } \\
\text { [Note: 积水 is used in } \\
\text { its dynamic and static } \\
\text { sense; not dead water } \\
\text { or puddles of water.] }\end{array}$ & $\begin{array}{l}\text { ponding; pondings; Too much water was } \\
\text { accumulated; accumulated water; filled } \\
\text { with water; numerous water; Raindrops } \\
\text { accumulated; rain water; rain } \\
\text { accumulating; standing water [3] }\end{array}$ & $\begin{array}{l}\text { filled with water; covered by pondings; } \\
\text { accumulated water; rainwater; covered by water; } \\
\text { the water covering the roadway; covered with } \\
\text { water; full of water; ponding; all water [3] }\end{array}$ \\
\hline & $\begin{array}{l}\text { (前后左右) 雨帘 } \\
\text { [Note: metaphor, } \\
\text { referring to heavy rain } \\
\text { pouring down] }\end{array}$ & $\begin{array}{l}\text { curtain of rain; curtain-like rain; rain } \\
\text { curtain; rain curtains; the rain; rain belts; } \\
\text { thousand chains; rain curtain; forming the } \\
\text { large curtains; pouring down from sky [7] }\end{array}$ & $\begin{array}{l}\text { rain was all round; curtains of rain; rain curtain; } \\
\text { rain curtain; rain fell from all sides; curtain of } \\
\text { rain; raining curtains; blinding rain; raining } \\
\text { curtains; curtain of rain; [8] }\end{array}$ \\
\hline & $\begin{array}{l}\text { (商店) 廊下 } \\
\text { [Note: 廊 usu. the } \\
\text { passageway or corridor } \\
\text { outside a door] }\end{array}$ & $\begin{array}{l}\text { under the porch; under the eaves of shops; } \\
\text { the shop; the roof of a shop; under the shop } \\
\text { corridor; shop's corridor; the stores; 0; } \\
\text { under the corridor; under the roof [2] }\end{array}$ & $\begin{array}{l}\text { under the corridor; under the store's porch; hallway; } \\
\text { under the corridor of shops; in the corridor of } \\
\text { shops; under shop roofs; to the shop's corridors; } \\
\text { to stores; the store porch; under the shop porch [2] }\end{array}$ \\
\hline Perspective & (See analysis below) & $4 ; 2 ; 3 ; 3 ; 3 ; 3 ; 3 ; 2 ; 2 ; 1$ & $3 ; 1 ; 3 ; 2 ; 2 ; 4 ; 3 ; 2 ; 3 ; 2$ \\
\hline \multirow{2}{*}{$\begin{array}{l}\text { Prominence } \\
\text { (The } \\
\text { prominent } \\
\text { stage in the } \\
\text { process of } \\
\text { movement } \\
\text { is marked } \\
\text { by } \\
\text { numerals, } \\
\text { in which } \\
\text { the } \\
\text { bracketed } \\
\text { mark the } \\
\text { second } \\
\text { prominent } \\
\text { stage.) }\end{array}$} & $\begin{array}{l}\text { 下 车 [Note: the } \\
\text { process is: the } \\
\text { bicyclist dismounted } \\
\text { 1, pushed it forward 2, } \\
\text { stopped 3, took shelter } \\
\text { in a corridor 4] }\end{array}$ & $\begin{array}{l}\text { to stop } 3 \text {; hid themselves } 4 \text {; got off the bike } \\
1 \text {; got off bikes } 1 \text {; got off their bikes } 1 \text {; } \\
\text { stopped } 3 \text {; stopped } 3 \text {; went to the corridor } 2 \text {, } \\
3,4 \text {; got off } 1 \text {; fell off down their bikes [four } \\
\text { give prominence to } 1 \text {, three to } 3 \text {, one to } 4 \text {, } \\
\text { one extended translation, one unacceptable] }\end{array}$ & $\begin{array}{l}\text { stop } 3 \text {; forced the cyclists to find shelter } 1,2,3,4 \text {; } \\
\text { stopped } 3 \text {; stopped } 3 \text {; got off their bikes } 1 \text {; get off } \\
\text { their bikes } 1 \text {; seek shelter } 4 \text {; get off } 1 \text {; got off from } \\
\text { the bicycles } 1 \text {; went } 2 \text { [four give prominence to } 1 \text {, } \\
\text { three to } 2 \text {, one to } 3 \text {, one extended translation] }\end{array}$ \\
\hline & $\begin{array}{l}\text { (两条龙一起出动) } \\
\text { 奔考场 } \\
\text { [Note: the process is: } \\
\text { the bicyclist rode at a } \\
\text { rapid speed 1, to the } \\
\text { test room 1', (then } \\
\text { entered into the test } \\
\text { room 2, took the test } \\
\text { 3)] }\end{array}$ & $\begin{array}{l}\text { forged ahead into the examination room; set } \\
\text { off to the examining hall } 1 \text {; going to the } \\
\text { examination hall } 1 \text {; set out for the } \\
\text { examination hall } 1 \text {; rushing to the field of } \\
\text { examination } 1 \text {; rushing to take an } \\
\text { examination } 1,(3) \text {; rushing to take an } \\
\text { examination 1, (3); marched towards the } \\
\text { examination room } 1 \text {; go for the exam } 1,(3) \text {; } \\
\text { (not translated) [five give prominence to } 1 \text {; } \\
\text { three to 1, (3); two unacceptable } \\
\text { translations] }\end{array}$ & $\begin{array}{l}\text { to take the exam }(3) \text {; on the way; go out to the } \\
\text { examination room } 1 \text {; turned out to the examination } \\
\text { hall } 1 \text {; going to the examination hall } 1 \text {; rushing } \\
\text { to the examination } 1,(3) \text {; setting out forward to the } \\
\text { test } 1,(3) \text {; set off to the examination room } 1 \text {; rush } \\
\text { toward the examination place } 1 \text {; setting about to the } \\
\text { examination hall } 1 \text {. [six give prominence to } 1 \text {; two } \\
\text { to } 1,(3) \text {; one to (3); one that is other type than those } \\
\text { marked here] }\end{array}$ \\
\hline Specificity & $\begin{array}{l}\text { (你) 属龙, (我也 } \\
\text { 属龙) } \\
\text { [Note: no translation } \\
\text { of “属” marked as 1; } \\
\text { translation of “属”, 2; } \\
\text { addition of other } \\
\text { background } \\
\text { information, 3] }\end{array}$ & $\begin{array}{l}\text { Our animal sign is dragon 2; we two } \\
\text { dragons } 1 \text {; born in the year of the dragon } 2 ; \\
\text { You were born in the year of dragon 2; we, } \\
\text { both dragons } 1 \text {; You were born in the year } \\
\text { of dragon 2; You are under the sign of the } \\
\text { dragon 2; My daughter is a dragon, and I am } \\
\text { a dragon too 1; you are in the year of dragon } \\
2 \text { you are the dragon 1. } \\
\text { [four cases of } 1 ; \text { six of } 2 \text { ] }\end{array}$ & $\begin{array}{l}\text { belong to dragon } 1 \text {; born in the year of dragon } 2 \text {; } \\
\text { were born in Chinese year of dragon } 2 \text {; both under } \\
\text { the zodiac sign of the dragon } 3 \text {; us, both under the } \\
\text { dragon sign } 2 \text {; your and my animal sighs are dragon } \\
2 \text {; you belonged to the Zodiac dragon } 3 \text {; born in the } \\
\text { year of dragon } 2 \text {; born on the year of dragon(the } \\
\text { Chinese use twelve animals to represent twelve } \\
\text { years) } 3 \text {; born in the year of dragon } 2 \text {. } \\
\text { [one case of } 1 \text {; six of } 2 \text {; three of } 3 \text { ] }\end{array}$ \\
\hline
\end{tabular}

With regard to the perspective analysis, the authors here take the Chinese sentence “路面上是积水, 前后左右都是 雨帘, 许多骑车的人都下车躲到商店廊下去避雨。” for example. Four types of perspectives can be found in the subjects' translations: 1. The narrator's perspective (e.g. "The road was covered by pondings, and the curtains of rain fell everywhere, which forced the cyclists to find shelter against rain under the store's porch.(2j)"); 2 . The sentence subject as the perspective (e.g. "With poundings on the road, and surrounded by the curtain-like rain, many bicyclers hid themselves under the eaves of shops.(2'j)"); 3 . A mixed perspective of the narrator and the sentence subject (e.g. "The road was filled with water and the rain was all around, and many cyclists had to stop to escape from the rain under the shop corridor.( $(1 j)$ "); 4. Confused perspective (e.g. "With ponding on the road and the curtain of rain around us, many passers by preferred to stop under the porch of the store to take shelter from rain. (1'j)").

It can be found from Table II that in scope, the PD group and the IR group do not show noticeable difference between themselves. In scope, there are too many translations which are not accurate by the two groups of translators compared against the original (for example, the translations of the Chinese“积水”and“廊下”), and there are some unacceptable collocations, for example, "below the corridor", which proves the inadequacy in English and encyclopedic knowledge on the part of the translators. In perspective, the two sides are different by $70 \%$, yet the difference seems to have little to do with the different translation tools. In terms of prominence, they show much less difference, and in this regard, the unacceptable translations by the PD group are a little more than those by the IR group. In terms of specificity, 
the two groups show much difference in that the translations with added words providing background information by the IR group are noticeably more than those by the PD group.

Analysis of the translations in other experiments produces similar results. Therefore, the overall analysis of all the translations in the ten experiments supports the conclusion that on the whole, the two groups are noticeably different in the four dimensions; a global trend is that the translations by the IR group are higher in specificity than those by the PD group. In the translations of other texts than the literary prose, the IR group is more accurate in scope with the Chinese original, which is more explicitly shown in the translations of some proper names or expressions which the subjects seldom touch in their study. For example,“《经济、社会和文化权利国际公约》”和 “中国外文局” in G, and“《天 演论》，《法意》和《原富》”in C. In this regard, the IR proves more helpful. In the PD group, seven subjects marked“《天演论》、《法意》和《原富》”as the “most difficult expressions”, and many translations by the group were not correct. In the IR group, however, only two subjects marked it as "most difficult expressions", and the translations by this group tended relatively to be accurate. As far as Chinese idioms are concerned, if it was easy to find the equivalents or explanations of the idioms in the paper dictionaries or the internet resources, the two groups showed not much difference in their translations of them. However, subjects in both groups tended to copy what they found. For example, for“精诚所至, 金石为开”in $\mathrm{H}$, the same translation accounted for more than a half of all those translations by the two groups respectively. For“封禅泰山”in E, the IR aided translations tend to be more accurate than the PD aided ones, which proves that it is easier for the IR aided subject to obtain relevant background information for his translation. It is also found in research that some information from internet may bring about negative influence on the translator’s translation. For example, for“亲仁善邻, 国之宝也”in F, the PD aided subjects, though they were not able to find any reference in the paper dictionaries available to them, translated according their understanding to produce many acceptable translations, but two subjects of the IR aided group copied "versions" they found in internet and produced "theory of Pro-Hui good neighbor" ( 3 ' $f$ ) and "good neighbor pro-Hui, a national treasure" (5' $f$ ), both of which are unacceptable. Therefore, it is important for the translators to develop adequate ability to judge whether information offered in internet is acceptable. On the whole, there is not noticeable difference in syntax between the two groups in their translations.

\section{B. Other Findings}

Many subjects reported that "It is easier to use internet as an aid in translating (6e)", "Anyway, it is fast to find information for reference in the internet $(7 g)$ ", "The information in my paper dictionary is not sufficient (5'g)", "It is slower to refer to paper dictionaries, and the explanations in them are basically on the word level, so it is hard for me to find sentences for reference (4h)". Only one subject concluded that though using paper dictionaries was slower, if it was necessary to distinguish the subtle difference in meaning between synonyms and choose proper words in translation, he preferred to use paper dictionaries $(2 \mathrm{~h})$ ".

According to the subjects' experiment reports, the order of the translation tools available online in terms of their use frequency is Google Search Engine (45\%), Kingsoft Powerword and its translation function (32\%), You Dao Dict and its translation function (26\%), the translation function of China Online Translation Network (13\%), Iciba (9\%), others $(5 \%)$. No subject used specialized corpuses as translation aids. The paper dictionaries used by the subjects included various dictionaries, most of them being medium-sized Chinese-English dictionaries and English-English dictionaries.

As far as the procedure of translating is concerned, most subjects followed "first read through the whole text and then on the basis of a thorough understanding of it, translate sentence by sentence, and when meeting difficult words or expressions, consult the dictionaries (5'a)." or "read the whole text in Chinese for a rough idea, and use internet dictionaries or translation functions in translating difficult words, and by virtue of grammar knowledge of English I have learnt, connect English words and phrases into sentences $(2 a)$."

By the archives of the translated texts of the same original text, it is easier to find out the common synchronic difficulty on the part of the translators who translate the same original text, and by the translations produced by the same translator in the archives over the period of study, it is convenient to observe the diachronic progress made by the same translator (Bowker 2007:171). Here the authors only take the Chinese text and its translations in the ninth experiment for example and analyze the synchronic trouble with the translations. According to the 20 reports, with regard to “the most difficult words”, the high frequent words include“保驾” (21 times);“冲剂”(14 times);“精致” (12 times);“提神” (10 times). For the “most difficult sentences”, the reported sentences are “喝了一袋西洋参冲剂, 吞下 两粒西洋参胶囊, 临走时嘴里还含上几片西洋参片。”(18times); “有这么多西洋参保驾, 营养和精力当不成问 题了。”(10 times). For “other difficulties”, the reported ones include “sentence structure (9times); sentence cohesion, coherence and use of conjunctive words (8 times); translation of Chinese sentences without explicit subjects (7 times); text style and mood (6 times), translation of Chinese quantifiers (4 times). The words or expressions which are regarded by the subjects as the most difficult are mainly those which need to be rendered in a creative way in their context. In this regard, the two groups show little difference in their translations.

As regards the more specialized texts with more technical terms, for example, the regulation text in B and the business contract text in D, the IR aided subjects tend to think that "Though I seldom translated business texts, and I felt it was not easy to translate the text, I could find some translated sentences in the internet which were similar with the 
sentences I was transalting, so I was able to do it (4'd)." "It is more convennient to use internet in finding referecnes $\left(8^{\prime} d\right)$." "Though the internent reseources are easy to use than paper dictionaries, we should not accept them blindly $\left(7^{\prime} b\right)$ ". By contrast, the PD aided subjects tend to think that "there are too many techincal terms in the text, but I know little of them, so I had a hard time in translating them (7d)", "It is difficult to translate the text because it contains many specizlied terms, of which there are many I do not know how to render (5b)". Therefore, under the conditions of the experiments, using internet resources is more helpful to the subjects when they try to understand and render more specialized texts in genreral and technical terms in particular.

\section{CONCLUSION}

The main findings of the study are: as far as the construal of the original text by Chinese EFL majors is concerned, internet resources are more useful, especially in the construal dimensions of scope and specificity, compared with paper dictionaries in helping them to overcome their inadequacy in encyclopedic knowledge and relevant specialized knowledge, thus more significant to them in translation practices; Judging on the basis of the subjects' translations, the two sources of information do not show noticeable difference in terms of prominence, especially when it comes to the words and sentences which should be render in a creative way. In perspective, though there is remarkable difference between the two sides, the difference seems to have little to do with the different translation tools. It should be pointed out that the study is limited in that when analysis of construal is conducted, it is impossible to distinguish the influence of different sources of information on the process of understanding the original text and that on the expression process in translating. Pedagogically, it is found by the study that the performance of the subjects in using the internet resources to aid their translation need to be improved, and the translation teachers should make more efforts to teach ways of efficient application of translation technology to translation learners, which involves online information searching skills. It is also worth mentioning that the translator's ability to judge whether what he finds in the internet is dependable and proper for his translation purpose depends mainly on his bilingual proficiency and his adequate analysis of the factors confining his translation task, which constitute a necessary condition for him to take full advantage of the internet to aid his translating.

\section{REFERENCES}

[1] Bowker, L. (2007). Corpus-based Applications for Translator Training: Exploring the Possibilities. In S. Granger, et al (eds.) Corpus-based Approaches to Contrastive Linguistics and Translation Studies. Beijing: FLTRP, 169-184.

[2] Fauconnier, G. (1994). Mental Spaces. New York: Columbia University Press.

[3] Langacker, R. W. (1987). Foundations of Cognitive Grammar. Vol. 1: Theoretical Prerequisites. Stanford, California: Stanford University Press.

[4] Snell-Hornby, M. (1995). Translation Studies: An Integrated Approach (Revised Edition). Amsterdam: John Benjamins Publishing Company.

[5] Wang, Xiaonong \& Zhang Fuyong. (2009). English Sentence Patterns and Translation from Chinese into English: Incorporating Insights of Cognitive Linguistics. Chengdu, Sichuan, China: Southwest Jiaotong University Press.

[6] Wang, Yin. (2008). The Interpretation of Subjectivity-objectivity in Translation by Means of "Embodied Conceptualization" An Analysis of 40 English Translations of the Chinese ancient poem "Feng Qiao Ye Bo". Foreign Language Teaching and Research (3): 211-217.

Xiaonong Wang (corresponding author) was born in 1968 in Zibo, China. He received his MA degree in linguistics from Shandong University, China, in 2003. He is now doing a doctoral program in College of Foreign Languages, Nankai University, Tinjian, China.

He is currently an associate professor in School of Foreign Languages, Ludong University, Yantai, Shandong, and has worked as a teacher of translation and translator between Chinese and English for more than a decade. Interested in translation studies from a cognitive perspective, he co-authored two books on study of textual translation on the basis of Cognitive Linguistics. He is also the author of a book on applying English for practical purposes with special reference to translation from Chinese into English, and published a series of scholarly papers concerned with teaching translation to Chinese EFL majors on the university level.

Bo Chang was born in 1971 in Zibo, China. She received his BA degree in Literature from Ludong University, China, in 2010.

She is currently a lecturer in the Multimedia Instruction Management Center, Ludong University, Yantai, China. Her research interest is application of CAT in teaching. 